\title{
Editorial
}

\section{Urinary tract infection in children: preventing the havoc in India}

\author{
Snigdha Sharma* \\ Mahatma Gandhi Institute of Medical Sciences, Sevagram, Maharashtra, India \\ Received: 01 November 2021 \\ Accepted: 08 December 2021 \\ *Correspondence: \\ Dr. Snigdha Sharma, \\ E-mail: sharma.snigdha14@gmail.com
}

Copyright: () the author(s), publisher and licensee Medip Academy. This is an open-access article distributed under the terms of the Creative Commons Attribution Non-Commercial License, which permits unrestricted non-commercial use, distribution, and reproduction in any medium, provided the original work is properly cited.

Urinary tract infection (UTI) remains one of the most common causes of febrile illness in paediatric practice ranking next to gastrointestinal and respiratory tract infections as the third most common bacterial infection in children in the developing countries. ${ }^{1}$ According to World Health Organization (WHO) in developed countries, UTI is diagnosed in $1 \%$ of boys and 3-8\% of girls. In the first year of life, UTI is more prevalent in boys with rates of $2.7 \%$ compared with $0.7 \%$ in girls. Most infection in boys occur in the first 3 months of life but by school age, the rate has decreased in boys and increased in girls. Several studies have been conducted to determine UTI prevalence in developing countries and have shown a higher UTI prevalence of $8-35 \%$ in malnourished children with the risk of bacteriuria increasing significantly with the severity of malnutrition. ${ }^{2}$ The epidemiological data collected by several studies states that, in India, UTI is one of the most common bacterial illness among febrile infants and preschool children with a reported prevalence between $4.1 \%$ and $7.5 \% .^{3}$ During the first year of life, the incidence of UTI in girls is $0.7 \%$ compared with $2.7 \%$ in boys. ${ }^{4}$ In uncircumcised boys, during the first 6 months, there is a 10 to 12 -fold increased risk for developing UTI. In children aged 1 to 5 years, the annual incidence of UTI is $0.9 \%$ to $1.4 \%$ for girls and $0.1 \%$ to $0.2 \%$ for boys. ${ }^{5}$ The incidence of a UTI is largely unchanged from age 6 to 16 years, with an annual incidence of $0.7 \%$ to $2.3 \%$ for girls and $0.04 \%$ to $0.2 \%$ for boys. ${ }^{[6]}$ There is a large number of literature discussing the prevalence and approach to UTI and yet there is paucity of discussion about the need of introducing sanitation and hygiene of genitals as a major contributing factor to UTI since childhood and their improvement to reduce its prevalence, especially in developing countries. Through this article, we aim on raising concern and awareness about proper hygiene of genitals and cleaning practices among parents to prevent UTI starting as early as childhood.

\section{Genital hygiene}

The stigma around discussion about genitals and their hygiene is a major obstruction in spreading awareness and introducing sanitary practices to promote intimate hygiene early in childhood so that children can be conditioned into taking genital hygiene seriously and make intimate washing a routine habit. When children start toilet training, good bathroom habits should be taught to them too as they will adapt them early in life. There are several modules available to guide parents/guardians in providing proper genital hygiene to kids but a channel is required to counsel the parents regarding the same, a role which must be played by a healthcare professional.

UTI can be prevented by taking simple measures like: changing diapers more often, after each bowel movement, girls should wipe from front to rear and not rear to front. This keeps germs from spreading from the anus to the urethra. Urine sitting in the bladder too long gives bacteria a good place to grow, therefore, children should be explained to not hold it in and inform whenever they need to go to the toilet.

There are different methods of intimate washing in different conditions in both boys and girls which must be explained to parents soon after birth.

\section{Cleaning genitals in boys}

At birth, the penis is covered by a double fold of skin, called foreskin. Circumcision is a practice in few cultures where this foreskin is removed. Care of the circumcised 
and uncircumcised penis is different which should be explained to parents soon after birth by the healthcare provider.

\section{For uncircumcised penis}

During the first several years of life, the intact foreskin will naturally separate from the glans. This is called foreskin retraction. Foreskin retraction should never be forced. Until it fully separates, do not try to pull it back. Forcing it to retract before it is ready can cause severe pain, bleeding, and tears in the skin.

Steps to clean include: wash all body including genitals, when giving bath to your infant; wash the head of the penis and the inside fold of the foreskin with soap and water; and watch your baby urinate to be sure that the hole in the foreskin is large enough to allow a normal stream.

Kids should be taught to clean their genitals in the following way: step 1 - gently pull the foreskin back away from the end of the penis; step 2 - rinse underneath the foreskin with soap and warm water; and step 3 - pull the foreskin back over the penis.

If the foreskin becomes considerably red or swollen, a paediatrician must be consulted. If the foreskin is fully retracted before puberty, an occasional retraction with cleansing beneath will do.

\section{For circumcised penis}

Usually, after the circumcision has healed, the penis requires no additional care. During the bath, soapy water can be squeezed over the penis from a washcloth and rinse it.

Occasionally a small piece of the foreskin remains which should pull back gently each time the child is bathed. The groove around the head of the penis is examined and made sure it's clean.

\section{Steps to clean while diaper change}

The baby's bottom and surrounding dirty areas should be wiped with a sensitive baby wipe (alcohol and fragrance free), moist tissue, or damp washcloth using only plain water. In boys, the groove between scrotal sacs and thighs must be cleaned properly. The penis is tucked into a downward position just before putting a fresh diaper to avoid urine to escape over the top end of the diaper. ${ }^{8}$

\section{Cleaning genitals in girls}

During bath, avoid getting soapy water inside the vagina as it is an irritant. Be careful while giving bubble baths, avoid using harsh soaps and body washes. They may strip the natural protective layer of the vagina.

Clean by running a washcloth up each side of the labia, between the inner and outer labia. Always clean from front to back and never from back to front, to avoid UTIs.
Rinsing off the soap from the vulva is very important. Kids should be taught to clean their own vulva and shown them exactly where this is, and explain what each part is called and why it's important to clean it. The vagina is the part on the inside; the vulva is on the outside, and includes all 'external genitalia' - the labia (four lips), the clitoris and the opening of the urethra (for urine).

The vagina cleans itself, so unless there is something up there (like faeces), it should not be cleaned from the insides and soap must never be used to clean the insides of vagina.

\section{Steps to clean while diaper change}

For girls, the entire outside of visible soiling should be wiped firmly but gently, and then in between the outer labia and inner labia as required. Always wipe the area from front to back. Dry off with air or a dry cloth, but don't rub hard. ${ }^{9,10}$

Healthcare workers have been encouraging sanitation and hygiene since a long time especially in developing countries to combat communicable diseases, this review supports its inclusion national programmes to promote proper cleaning of genitals since birth to prevent UTI by infective causes. If started early, the healthy cleaning habits can significantly reduce UTI due to infective causes in children and consequently in adults. Several studies have shown association of developing UTI with factors like unclean latrines, improper handwashing, unclean clothes and improper menstrual hygiene but not much focus has been given to awareness of people about proper cleaning of genitals in kids and adults. ${ }^{11}$

A huge barrier in achieving genital health and reducing UTI in kids is tackling the stigma around the topic of intimate hygiene, there should be an initiative by healthcare workers to normalise genital cleanliness just like talking about treating diaper rashes or a healthy breastfeeding practice and spread awareness among parents about steps to clean a child's genitals and teach kids to do the same. It can be done by involving accredited social health activist (ASHA) and auxiliary nurse midwife (ANM) workers to spread awareness among parents in rural areas through pamphlets, skits and videos demonstrating proper steps followed by a module which will be distributed to parents soon after birth of the child to start early and prevent UTI in children and in adults in the long run.

\section{REFERENCES}

1. Uwaezuoke SN. The prevalence of urinary tract infection in children with severe acute malnutrition: a narrative review. Pediatr Health Med Therap. 2016;7:121.

2. World Health Organization. Urinary tract infections in infants and children in developing countries in the context of IMCI. World Health Organization. 2005. Available at: https://www.google.com/url?sa=t\& $\mathrm{rct}=\mathrm{j} \& \mathrm{q}=\& \mathrm{esrc}=\mathrm{s} \&$ source $=$ web $\& \mathrm{~cd}=\& \mathrm{cad}=\mathrm{rja} \& \mathrm{uac}$ 
$\mathrm{t}=8 \&$ ved=2ahUKEwibqpPHjOH0AhVP7XMBHfjf BccQFnoECA4QAQ\&url=https\%3A\%2F\%2Fwww. who.int $\% 2$ Firis $\% 2$ Fhandle $\% 2 F 10665 \% 2 F 69160 \& u$ sg=AOvVaw1 VLduH7-sp02bhtFRPXBsH.

Accessed on 14 August 2021.

3. Shetty PN, Prashanth S, Jagadeeshwara S. Prevalence of urinary tract infection among preschool febrile children attending the pediatric OPD. Int J Contemp Pediatr. 2017;4(2):561-7.

4. Zorc JJ, Kiddoo DA, Shaw KN. Diagnosis and management of pediatric urinary tract infections. Clinical microbiology reviews. 2005;18(2):417-22.

5. Gholizadeh M, Eftekhari Z, Nagaraju K. Evaluation and Monitoring the Management of Urinary Tract Infection in the Department of Paediatric, Kempegowda Institute of Medical Sciences (Kims) Hospital and Research Centre, Bangalore, India. Arch Pharm Pract. 2020;1:114.

6. Ahmed SM, Swedlund SK. Evaluation and treatment of urinary tract infections in children. American family physician. 1998;57(7):1573.

7. Gholizadeh M, Eftekhari Z, Nagaraju K. Evaluation and Monitoring the Management of Urinary Tract Infection in the Department of Paediatric, Kempegowda Institute of Medical Sciences (Kims)
Hospital and Research Centre, Bangalore, India. Arch Pharm Pract. 2020;1:114.

8. American Academy of Pediatrics. The AAP Parenting Website. Available at: http://www.healthy children.org. Accessed on 14 August 2021.

9. Whiting F. How should I care for my baby girl's genitals? Babycentre. Available at: https://www.baby centre.co.uk/x1053619/how-should-i-care-for-mybaby-girls-genitals. Accessed on 14 August 2021.

10. How to clean a child's vulva and vagina. My vagina. Available at: https://www.allthingsvagina.com/howto-clean-a-childs-vulva-and-vagina/. Accessed on 14 August 2021.

11. Ademas A, Adane M, Sisay T, Kloos H, Eneyew B, Keleb A, Lingerew M, Derso A, Alemu K. Does menstrual hygiene management and water, sanitation, and hygiene predict reproductive tract infections among reproductive women in urban areas in Ethiopia? PloS One. 2020;15(8):e0237696.

Cite this article as: Sharma S. Urinary tract infection in children: preventing the havoc in India. Int J Community Med Public Health 2022;9:528-30. 